Física de la Tierra

ISSN-e: 1988-2440

http://dx.doi.org/10.5209/FITE.57688

\title{
Grandes terremotos en la región Ibero-Mogrebi
}

\section{Prólogo}

La sismicidad de la región Ibero-Mogrebí (RIM) se caracteriza por la ocurrencia de grandes terremotos separados por largos intervalos de tiempo. La frecuencia con que ocurren estos grandes sismos varía, siendo mayor en el este de la región (Argelia) y menos frecuentes aunque de mayor tamaño en el oeste (cabo de San Vicente). En el volumen, 29 de Física de la Tierra se ha querido recopilar la información existente de los grandes terremotos ocurridos en esta zona y los daños que han ocasionado, de forma que el lector tenga en una monografía una visión general de las características de los grandes sismos de RIM, distribución de intensidades, etc. En el volumen no se incluyen algunos de los mayores terremotos ocurridos en la región como los de Torrevieja de 1829 o Arenas del Rey de 1884, ya que estos terremotos han sido objeto de numerosas monografías y estudios detallados. La excepción es el sismo de Lisboa de 1755 , del que se presenta un trabajo, en el que por primera vez, se analizan de forma conjunta los daños causados por el terremoto en Portugal, España y Marruecos y no de forma individual, como ocurre en la mayoría de los trabajos existentes.

El volumen comienza con el trabajo de Udías, que presenta un riguroso análisis de los grandes terremotos ocurridos en la Península Ibérica antes de 1900 y recogidos en los diferentes catálogos, discutiendo las características de los mismos. El artículo de Caldeira et al. está dedicado a los grandes terremotos del archipiélago de Azores con una recopilación de los sismos ocurridos en las islas con intensidad igual o superior a VII desde el periodo histórico hasta nuestros días, incluyendo un análisis sismotectónico de la zona. El siguiente trabajo es el de Martínez Solares, dedicado al terremoto de Lisboa de 1755. Aunque existe numerosas publicaciones sobre este terremoto, el autor presenta los daños del terremoto en Portugal, España y Marruecos, lo que constituye una novedad, ya que la mayoría de las publicaciones existentes corresponden a los daños y efectos del terremoto en cada uno de estos países.

El artículo de Teves-Costa at al. está dedicado a los grandes terremotos ocurridos en la zona del Bajo Tajo, y que afectaron a la zona de Lisboa el de 1531 y 1909, y por tanto con diferente tipo de información. Para el de 1531 la fuente de información es la documentación histórica: informes, relatos etc, mientras que para el de 1909 ya existen sismogramas, por lo que se puede abordar su estudio con otras técnicas. Una parte del trabajo está dedicado al marco sismotectónico del Bajo Tajo. El trabajo de Batlló et al., tiene como objetivo una revisión de los terremotos de 1427 y 1428 del NE de España, sus principales parámetros sísmicos y su influencia en el estudio del riesgo sísmico de la zona. Los terremotos de Montesa (Valencia) de 1748 y Orán (Argelia) de 1790 son el tema del trabajo de Buforn et al., y en el que los autores realizan un estudio comparativo entre las características y diferencias de estos dos terremotos que ocurren en el mismo siglo, en zonas de baja actividad sísmica, antes 
y después del gran terremoto de Lisboa. El trabajo de Martínez Solares y Batlló está dedicado a los terremotos de la Vega Baja del Segura (SE de España) de los que el más conocido y que causó mayores daños es el de Torrevieja de 1829. Los autores analizan de forma individual los sismos de esta zona de intensidad superior a VII ocurridos entre 1048 y 1919, asignando parámetros focales y re-evaluando la intensidad.

El trabajo de Cherkaoui et al. es el primero de los tres del volumen dedicado a terremotos de Marruecos y Argelia. En el texto de Cherkaoui et al., se analiza el terremoto de 1624 de Fez (Marruecos), el de mayor tamaño ocurrido en el norte de este país y que causó mayores daños. Se analizan los daños causados por el sismo, su correlación con las estructuras geológicas de la zona y cual de ellas puede ser la responsable del mismo. El texto de Yelles-Chauche et al., es un análisis de los grandes terremotos ocurridos en la zona norte de Argelia desde el año 267 hasta nuestros días, región en la que terremotos con magnitud mayor que 6.5 son escasos. Se analizan estos sismos en el marco sismotectónico de la zona. El último trabajo es el de Bezzeghoud et al., es un análisis de tres grandes terremotos ocurridos en el periodo instrumental en Argelia: los sismos de El Asnam de 1954 y 1980, y el de Zemouri de 2003. Los autores presentan una recopilación de los parámetros focales y daños causados por los tres terremotos.

Las editoras queremos dedicar el volumen 29 de Física de la Tierra al recientemente fallecido Dr. Alfonso López Arroyo, que fue subdirector del Instituto Geográfico Nacional, experto en sismicidad histórica y pionero en la disciplina de ingeniería sísmica en España. Con este volumen queremos rendirle nuestro tributo y agradecimiento por abrir nuevas líneas de investigación y reconocer su liderazgo en el campo de la sismicidad histórica.

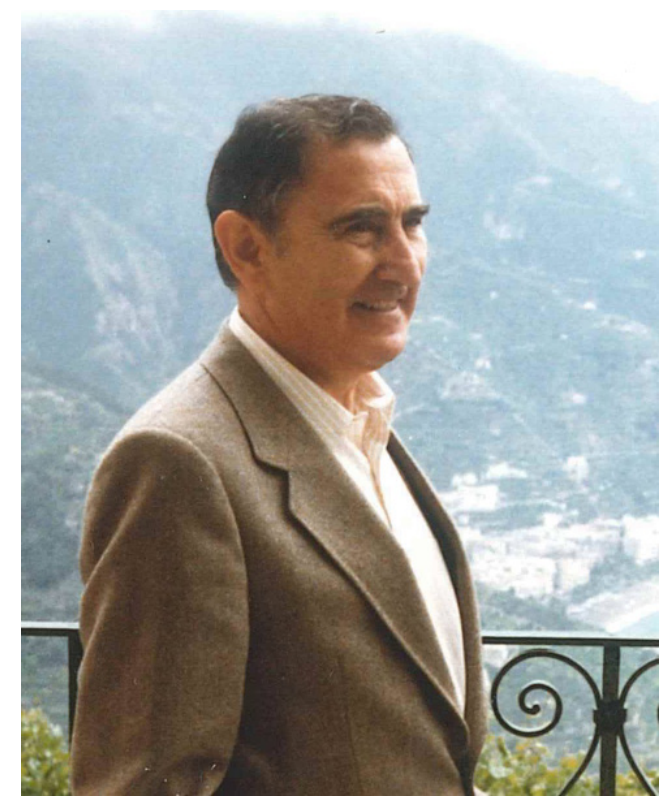

Dr. Alfonso López Arroyo (1927-2017) 